\title{
Análise da capacidade de suporte em áreas protegidas: a Área de Proteção Ambiental do Estuário do Rio Ceará e o Parque Botânico do Ceará, Fortaleza/CE
}

\author{
Analysis of support capacity in protected areas: the Environmental Protection \\ Area of the Ceará Estuary and the Ceará Botanical Park, Fortaleza/CE
}

Karinne Wendy Santos de Menezes ${ }^{1}$

1 Programa de Pós-Graduação em Geografia, Universidade Federal do Rio Grande do Sul. E-mail: karinnewendy@gmail.com

RESUMO: Este artigo tem a finalidade de avaliar a capacidade de suporte, por meio das potencialidades e limitações, assim como as condições ecodinâmicas e de vulnerabilidade, da Área de Proteção Ambiental do Estuário do Rio Ceará e do Parque Botânico do Ceará, unidades de conservação de uso sustentável e de proteção integral, respectivamente, localizadas na Região Metropolitana de Fortaleza/CE. O método sistêmico foi utilizado na pesquisa, metodologia da Ecodinâmica das Paisagens. Assim, foi realizada a contextualização dos sistemas ambientais identificados nas áreas. A análise da capacidade de suporte dos sistemas foi associada às condições de ocupação nas unidades de conservação.

Palavras-chaves: Sistemas Ambientais. Unidades de Conservação. Ecodinâmica.

ABSTRACT: This article has the purpose of evaluating the capacity of support, through the potentialities and limitations, as well as the environmental and vulnerability conditions, of the Environmental Protection Area of the Ceará River Estuary and the Ceará Botanical Park, of protected areas sustainable use and of integral protection, respectively, located in the Metropolitan Region of Fortaleza / CE. The systemic method was used in the research, Ecodynamics of Landscapes methodology. Thus, the environmental systems identified in the areas were contextualized. The analysis of the support capacity of the systems was associated with the conditions of occupation in the protected areas.

Keywords: Environmental Systems. Protected Areas. Ecodynamics.

Sumário: Introdução - 1 Metodologia - 2 Resultados e Discussões - Considerações Finais - Referências INTRODUÇÃO

As Unidades de Conservação (UC) foram criadas com o intuito de proteção ambiental, nas esferas federal, estadual e municipal em todo o território brasileiro, a partir da instituição do Sistema Nacional de Unidades de Conservação da Natureza (SNUC), com a publicação da Lei no 9.985 de 2000. O SNUC classifica as UC em Proteção Integral, que permitem apenas usos indiretos e Uso Sustentável, que permitem intervenções sociais e a utilização parcial de seus recursos naturais. Coelho et al. (2009) enfatizam que:

Unidades de conservação não dizem respeito apenas à proteção de ecossistemas ameaçados pela ação humana ou pela expansão do capitalismo. Nos últimos 30 anos, os discursos e as lutas políticas entre diferentes atores sociais envolvidos com a criação de unidades de conservação no Brasil foram gradativamente incorporando os direitos, responsabilidades e interesses das chamadas populações tradicionais (indígenas, seringueiros, caboclos, caiçaras, quilombolas, entre outras) ou das populações não 
consideradas tradicionais no entorno (COELHO, et al., 2009, p. 67).

Assim, os autores ressaltam as populações que dependem dos recursos naturais em UC e elucida o fato de que algumas destas no território brasileiro são utilizadas como proposta para a regularização fundiária e garantia dos direitos das populações tradicionais e essas áreas podem apresentar conflitos e contradições nas formas de uso, conforme o contexto na qual está inserida, como as áreas propostas.

Deste modo, este estudo tem o intuito de avaliar a capacidade de suporte do Parque Botânico do Ceará e da Área de Proteção Ambiental (APA) do Estuário do Rio Ceará, que se situam na Região Metropolitana de Fortaleza/CE. Na figura 01 é possível observar suas localizações.

Figura 01 - APA do Estuário do Rio Ceará e Parque Botânico do Ceará

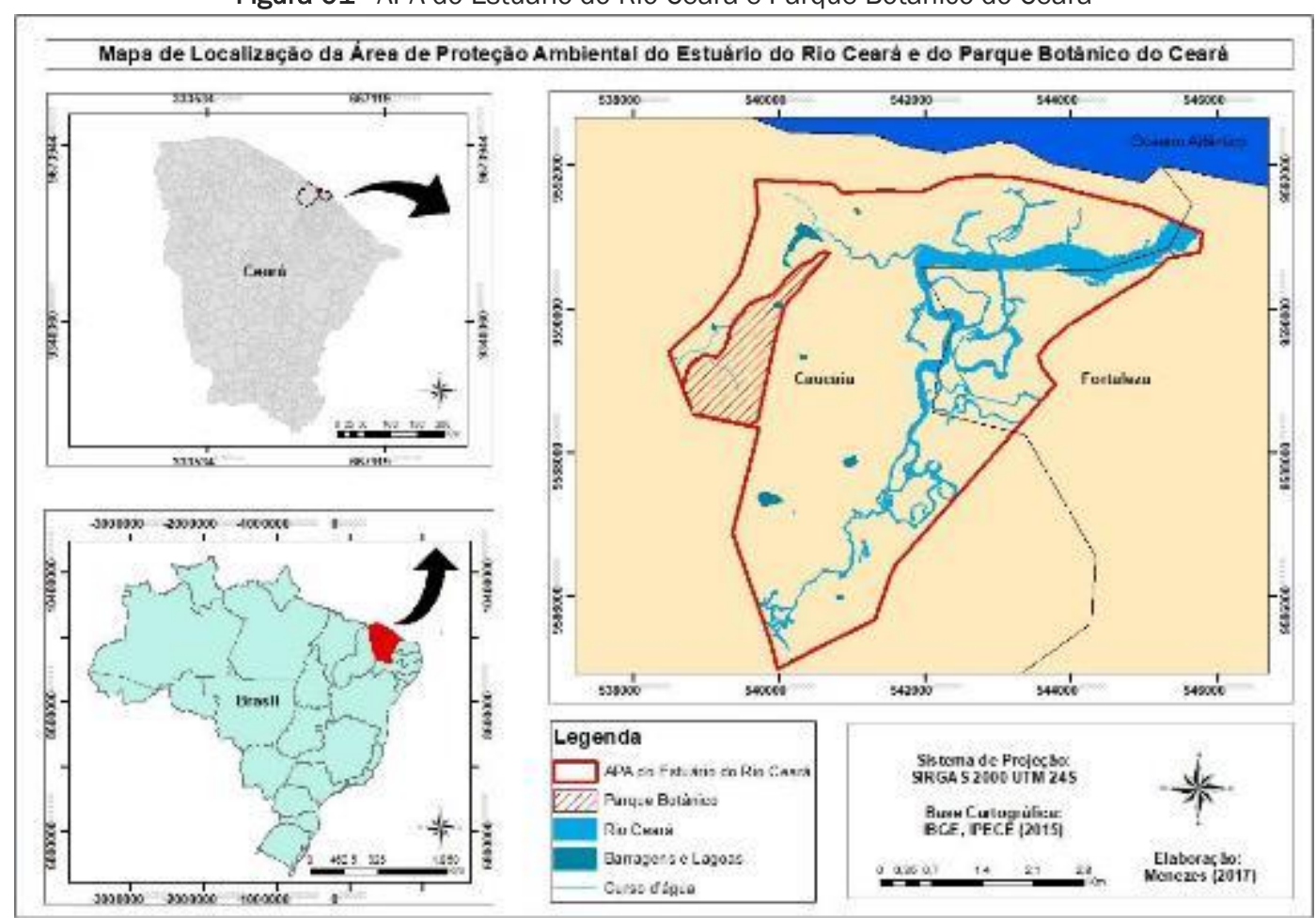

Fonte: Autora (2017)

O Parque Botânico do Ceará está localizado nos limites da APA do Estuário do Rio Ceará, com uma área de 190,00 hectares, no município de Caucaia, próximo a CE-90. É uma UC de proteção integral criada pelo Decreto Estadual n 24.216, de 09 de setembro de 1996, que ainda não está incluída no rol de categorias do SNUC (SEMACE, 2017).

\section{METODOLOGIA}

A partir de uma visão sistêmica, Tricart (1977) destaca os fluxos de matéria e energia no ambiente e a relação dinâmica entre os componentes naturais, que permite avaliar as condições entre os processos pedogenéticos e morfogenéticos, que conduzem, respectivamente, a estabilidade e instabilidade dos ecossistemas e/ou geossistemas. Souza (2000) propõe uma adaptação a esta teoria e classifica os meios ecodinâmicos em meios medianamente estáveis, nos quais os processos pedogenéticos são predominantes.

Os ambientes de transição, em que as modificações entre os processos morfogenéticos e 
pedogenéticos ocorrem de forma gradual e as atividades socioeconômicas influenciam no predomínio dos processos de pedogênese e morfogênese e os meios instáveis ou fortemente instáveis, na qual a morfogênese é predominante. Assim, utiliza-se como base teórico-metodológica a Ecodinâmica das Paisagens de Tricart (1977), adaptada por Souza (2000).

A Teoria Geral dos Sistemas (TGS) foi proposta primeiramente por Ludwig von Bertalanffy, e pode ser utilizada por diferentes campos do conhecimento científico. A TGS propõe o rompimento gradual das especificidades que se encontra na geografia física, assim, os estudos integrados do meio, permitem uma visão de totalidade do mundo e analisa os componentes da natureza por meio de suas interconexões.

Para a realização desta pesquisa foi organizado e sistematizado as informações sobre a área de estudo, com o auxílio de técnicas de geoprocessamento para a elaboração dos mapas temáticos. As figuras 02 e 03 especificam os produtos geocartográficos utilizados para o mapeamento básico e temático da pesquisa.

Para esclarecer melhor este assunto Souza (2000) relaciona as condições ecodinâmicas com as características de vulnerabilidade e sustentabilidade ambiental, com base no potencial dos recursos naturais e nas limitações de uso e estado de conservação. A partir disso, o autor propõe as seguintes definições:

- Vulnerabilidade baixa: as áreas que apresentam características de sustentabilidade alta;

- Vulnerabilidade moderada: apresentam características de sustentabilidade moderada e;

- Vulnerabilidade alta: apresentam características de sustentabilidade baixa e muito baixa.

Figura 02 - Cartografia básica utilizada na pesquisa

Bases cartográficas utilizadas como referência nesta pesquisa

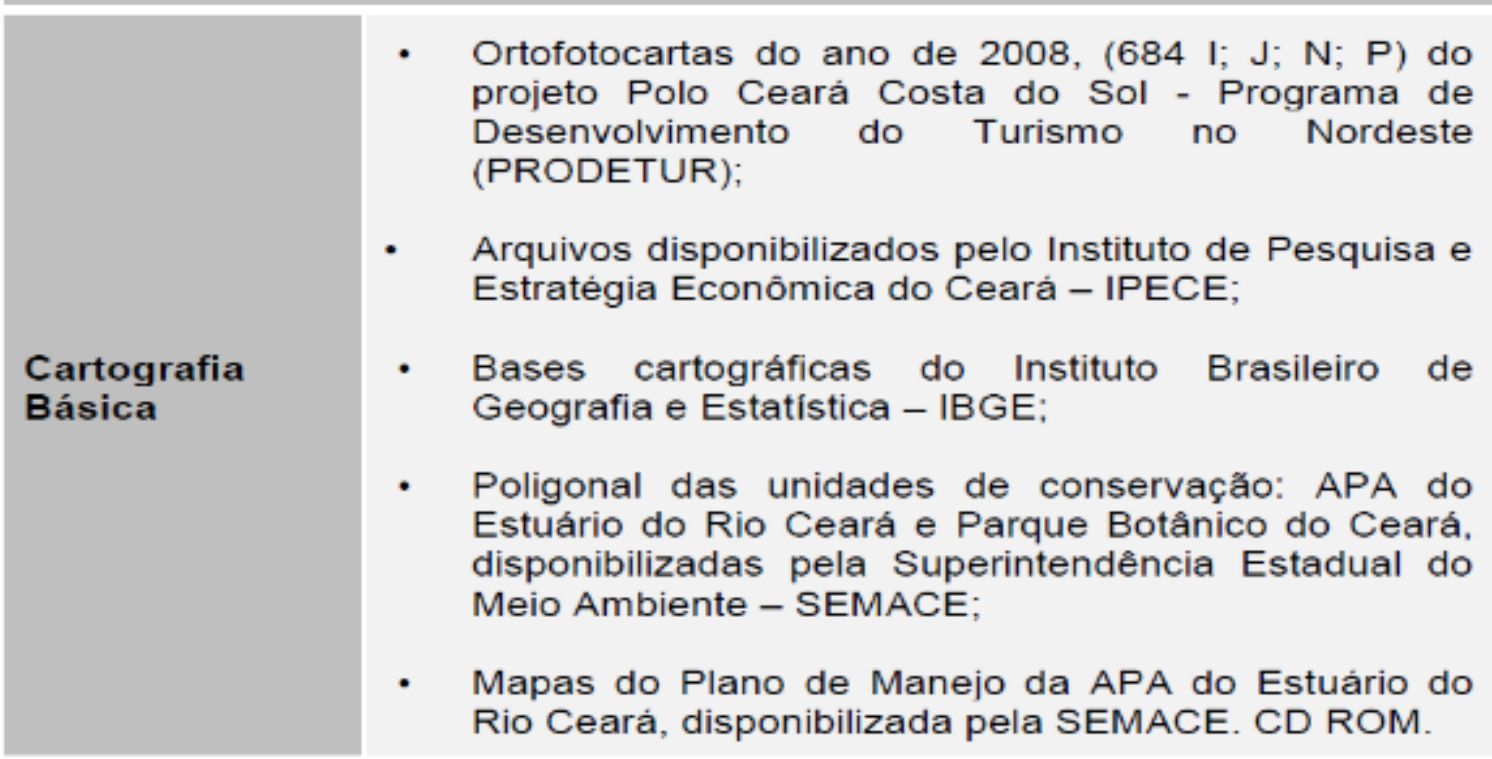

Fonte: Autora (2017). 
Figuras 03 - Cartografia temática utilizada na pesquisa

\section{Bases temáticas utilizadas como referência nesta pesquisa}

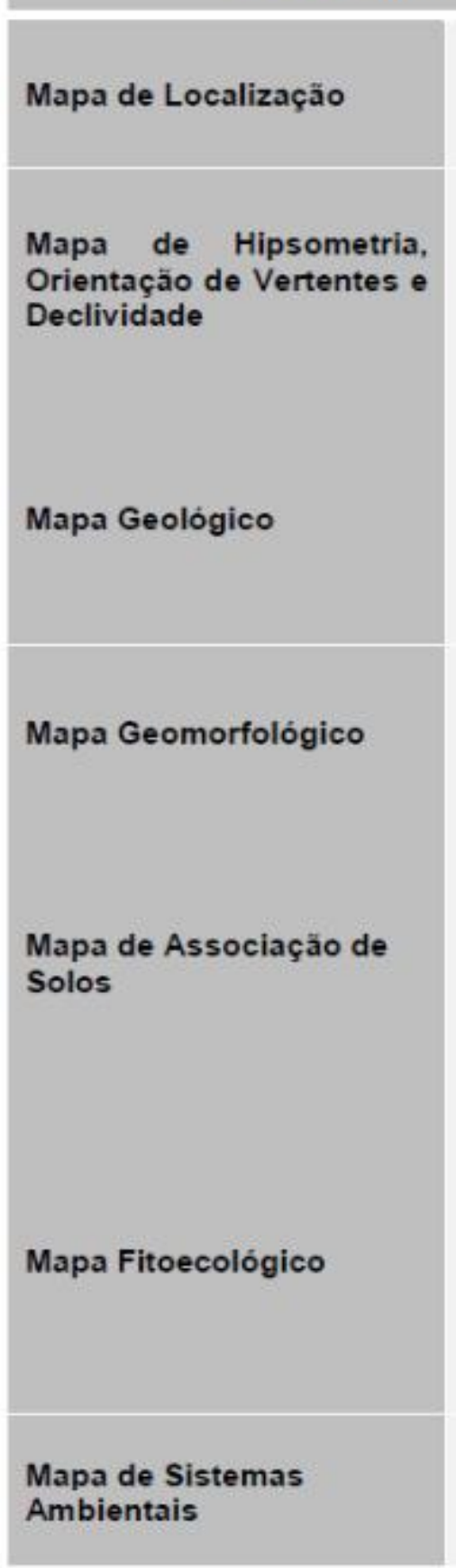

- Bases cartográficas do Instituto Brasileiro de Geografia e Estatistica - IBGE e pela Superintendência Estadual do Meio Ambiente SEMACE.

- Elaborados a partir do Modelo Numérico de Terreno (MNT);

- Dados SRTM (Shuttle Radar Topographic Mission) com precisão espacial de $30 \mathrm{~m}$;

- Utilizou-se relevo sombreado.

- Realizado a partir da interpretação da base cartográfica do Atlas Digital de Geologia e Recursos Minerais da CPRM/SRHCE (2003), na escala de 1:500.000;

- Informações das unidades litoestratigráficas e das constituições litológicas, fornecidas por SOUZA (2000).

- Utilizou-se para a elaboração deste mapa a interpretação das características geológica e geomorfológica das áreas em análise;

- Contribuições de Souza (2000).

- Utilizou-se o mapa exploratório de reconhecimento de Solos do estado do Ceará, na escala de 1:600.000, elaborado pela FUNCEME, disponiblilizado pelo IPECE.

- Elaborado a partir da análise das caracteristicas fisiconaturais dos aspectos geológicos e geomorfológicos da área mapeada.

- Mapa das Unidades Fitoecológicas do Estado do Ceará na escala de 1:600.000, elaborado pela Fundação Cearense de Meteorologia e Recursos Hídricos - FUNCEME e Universidade Federal do Ceará - UFC, disponibilizado no site do IPECE;

- Análise da Ortofotocarta do ano de 2008, (684 I; J; N; P) do projeto Polo Ceará Costa do Sol.

- Foi elaborado com base no mapeamento temático realizado, por meio das informaçōes geológicas, geomorfológicas, pedológicas e fitoecológicas.

Fonte: Autora (2017).

\section{RESULTADOS E DISCUSSÕES}

O mapeamento temático produzido a partir das bases cartográficas foram essenciais para compreender o contexto geoambiental das UC estudadas. A figura 04 apresenta a hipsometria, a orientação de vertentes e a declividade da APA do Estuário do Rio Ceará e Parque Botânico do Ceará. 
Figura 04 - Hipsometria, Orientação de Vertentes e Declividade

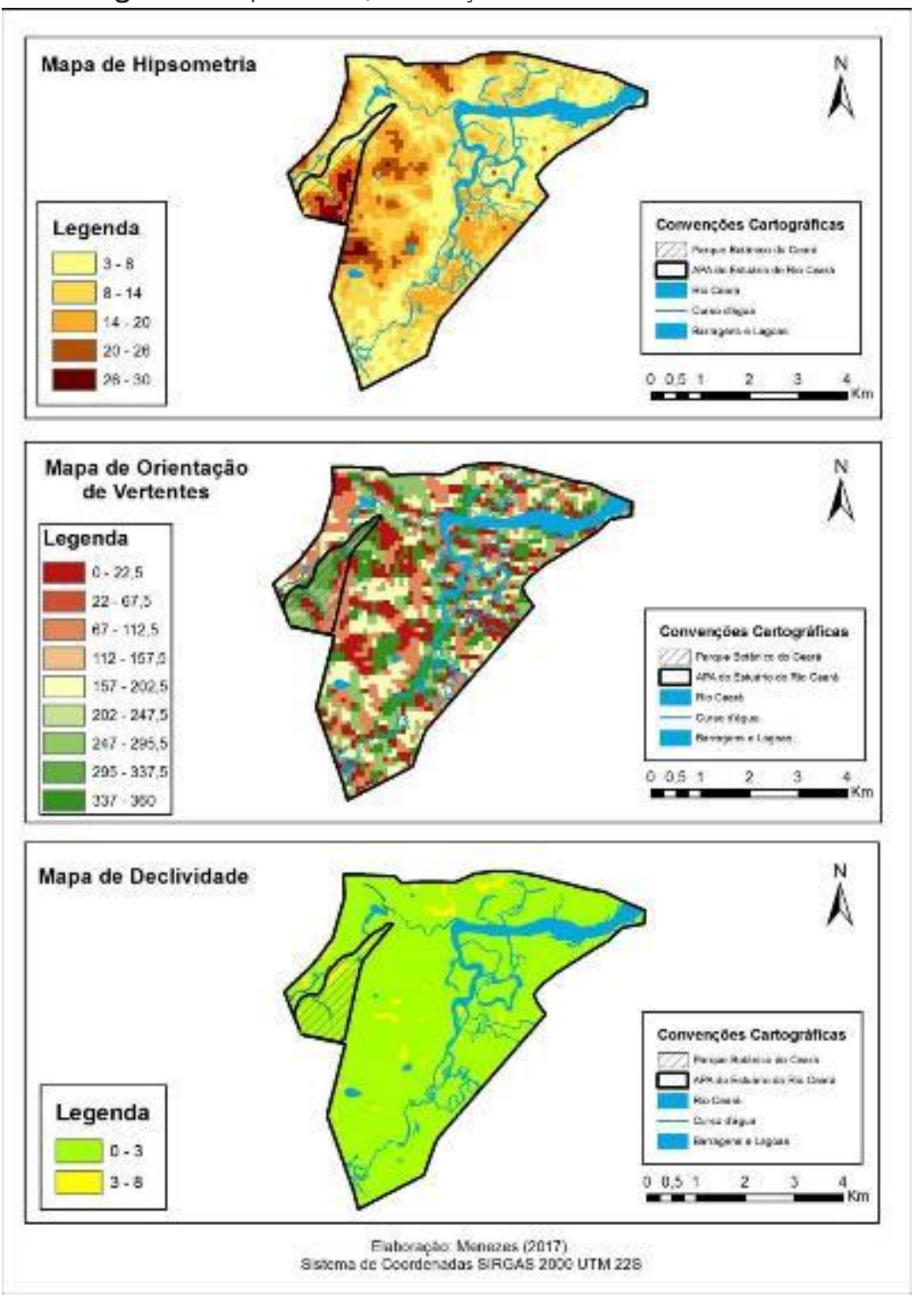

Fonte: Autora (2017).

Os mapas da figura 04 mostram que as áreas da APA do Estuário do Rio Ceará e do Parque Botânico do Ceará apresentam terras não susceptíveis ou pouco susceptíveis aos processos erosivos, solo relativamente plano, e que apresentam boas propriedades físicas, além de boa permeabilidade. A figura 05 e 06 trazem as unidades geológicas e geomorfológicas identificadas nas áreas em análise.

$\mathrm{Na}$ região nordeste do Brasil, o estado do Ceará apresenta eventuais secas e chuvas excepcionais, denota grande diversidade paisagísticas e diferentes domínios naturais. As condições geológicas do estado são variadas, apesar da predominância dos terrenos pré-Cambrianos de embasamento cristalino, enquanto na faixa litorânea se verificar a ocorrência de coberturas sedimentares dentríticas que foram depositadas ao longo da história geológica recente do território (SOUZA, 2007). 


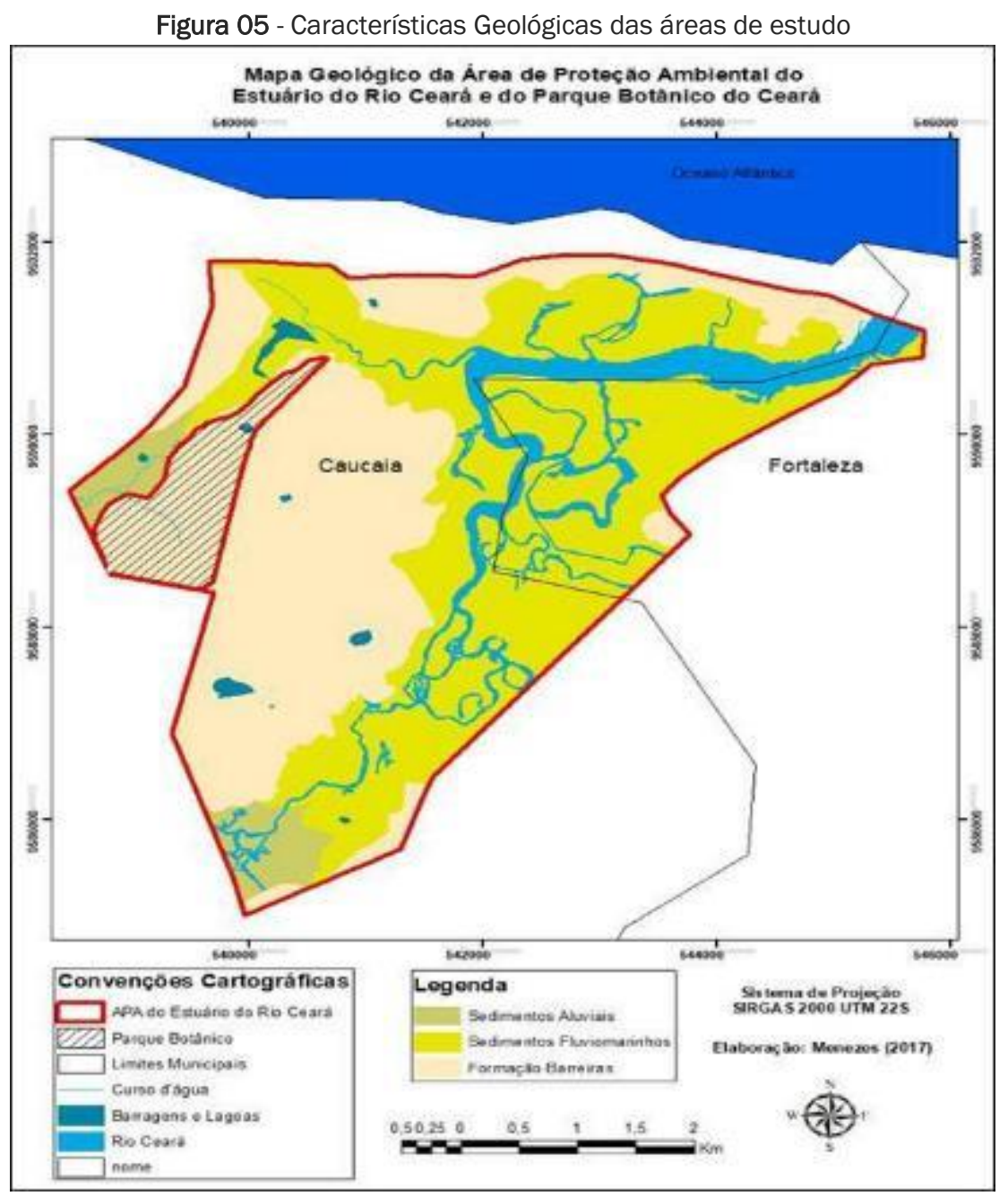

Fonte: Autora (2017).

De acordo com Souza et. al. (2009), no que se refere as características geomorfológicas, a planície fluviomarinha são áreas de complexas de acumulação, inundáveis periodicamente, apresentando depósitos continentais e acréscimo de sedimentos marinho, diferente da planície fluvial, que apresentam limitações ocasionadas por níveis escalonados de terraços mantidos ocasionalmente por cascalheiros. Os tabuleiros pré-litorâneos, presentes na APA e predominante no Parque Botânico, apresentam caimento topográfico suave, são áreas de acumulação dissecadas em interflúvios tabuliformes. 
Figura 06 - Características Geomorfológicas das áreas de estudo

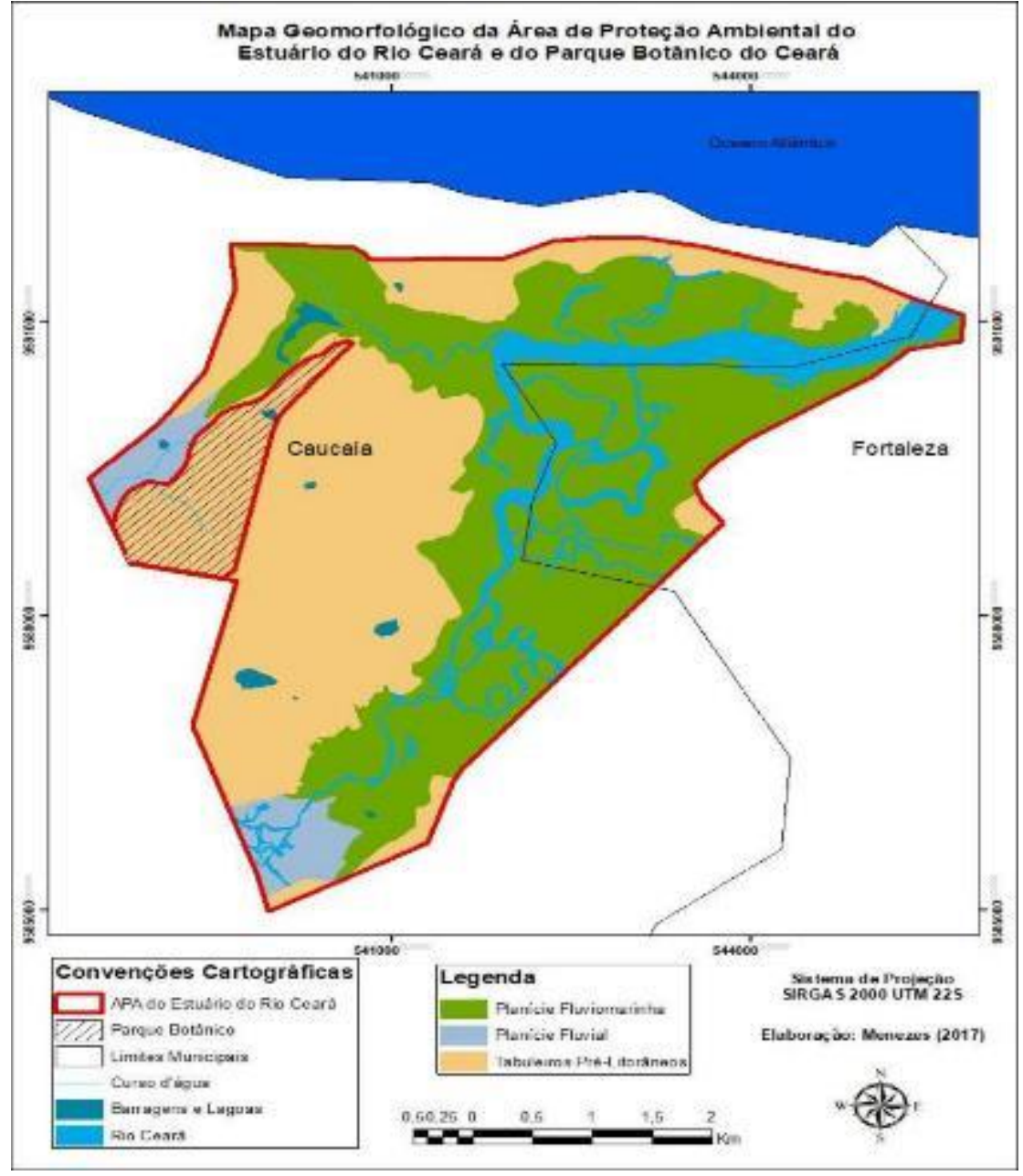

Fonte: Autora (2017).

A figura 07 e 08 retratam a associação de solos e a unidades fitoecológicas predominantes na APA e no Parque Botânico do Ceará. Na planície fluviomarinha do estuário do rio Ceará foram identificados gleissolos sálicos constituídos por vegetação halofítica gramíneo-herbácea e pela vegetação paludosa marítima de mangue. Enquanto na planície fluvial foram detectados neossolos flúvicos e planossolos compostos por mata ciliar. Os tabuleiros pré-litorâneos são formados pelos argissolos vermelho amarelos e neossolos quartzarênicos com a predominância da vegetação de tabuleiro. 


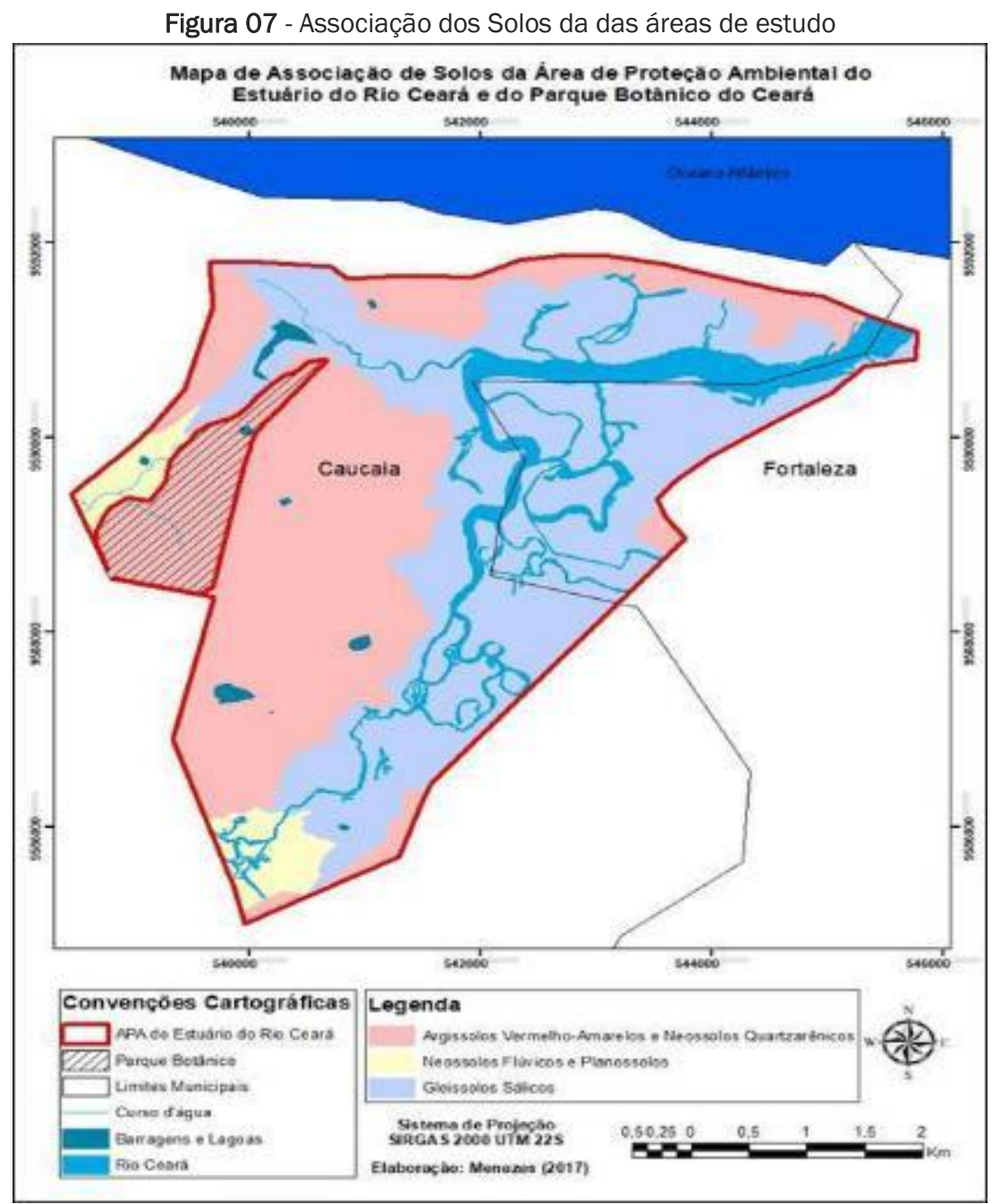

Fonte: Autora (2017).

A identificação dos componentes geológicos, geomorfológicos, fitoecológicos e a associação de solos da APA do Estuário do Rio Ceará foram importantes para a identificação dos sistemas ambientais presentes nestas UC. A figura 09 mostra os sistemas ambientais identificados e foi demarcada a área urbana presente nestas UC, com objetivo de identificar os possíveis conflitos de uso. 
Figura 08 - Mapa Fitoecológico das áreas de estudo

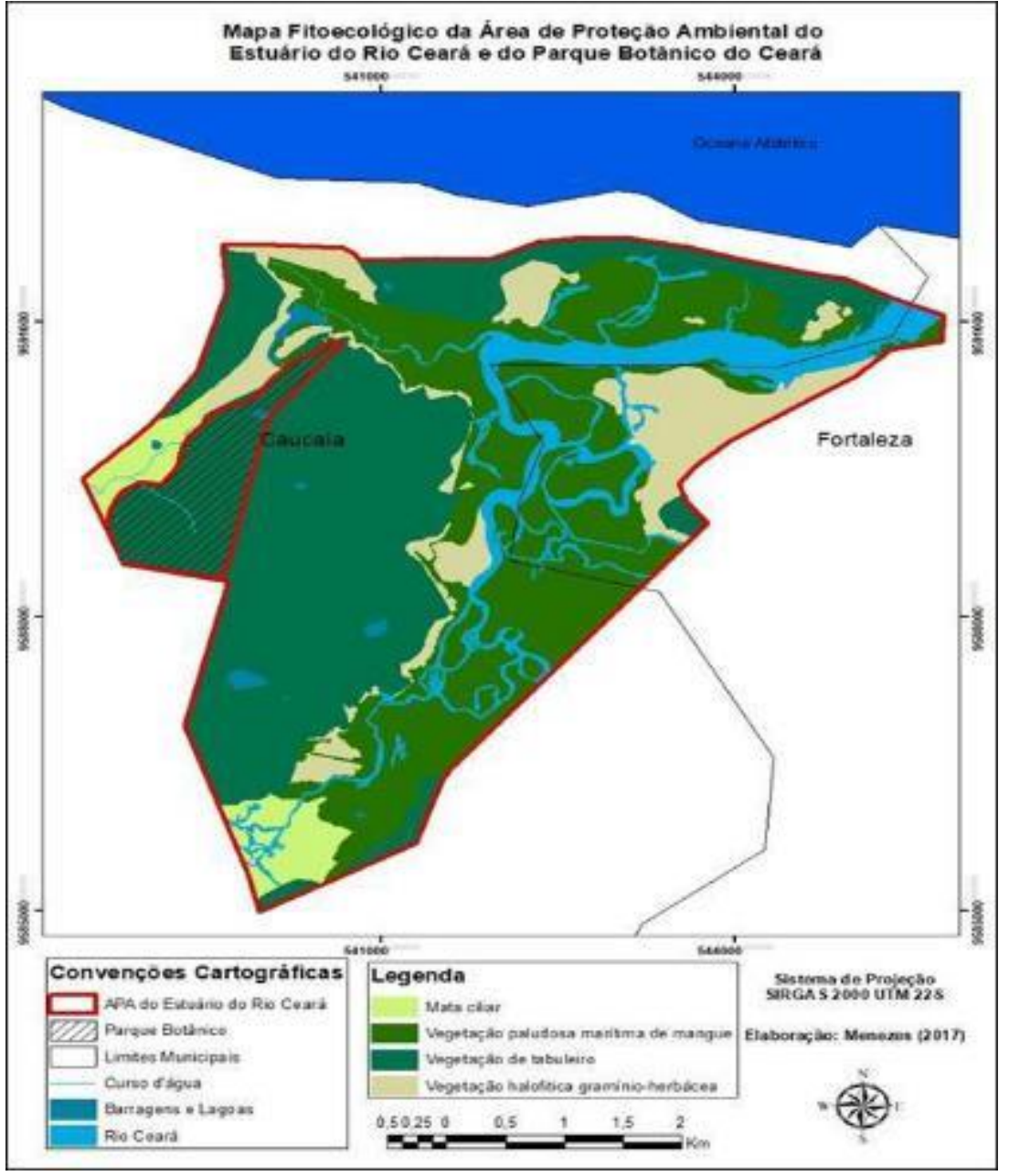

Fonte: Autora (2017). 
Figura 09 - Mapa dos Sistemas Ambientais

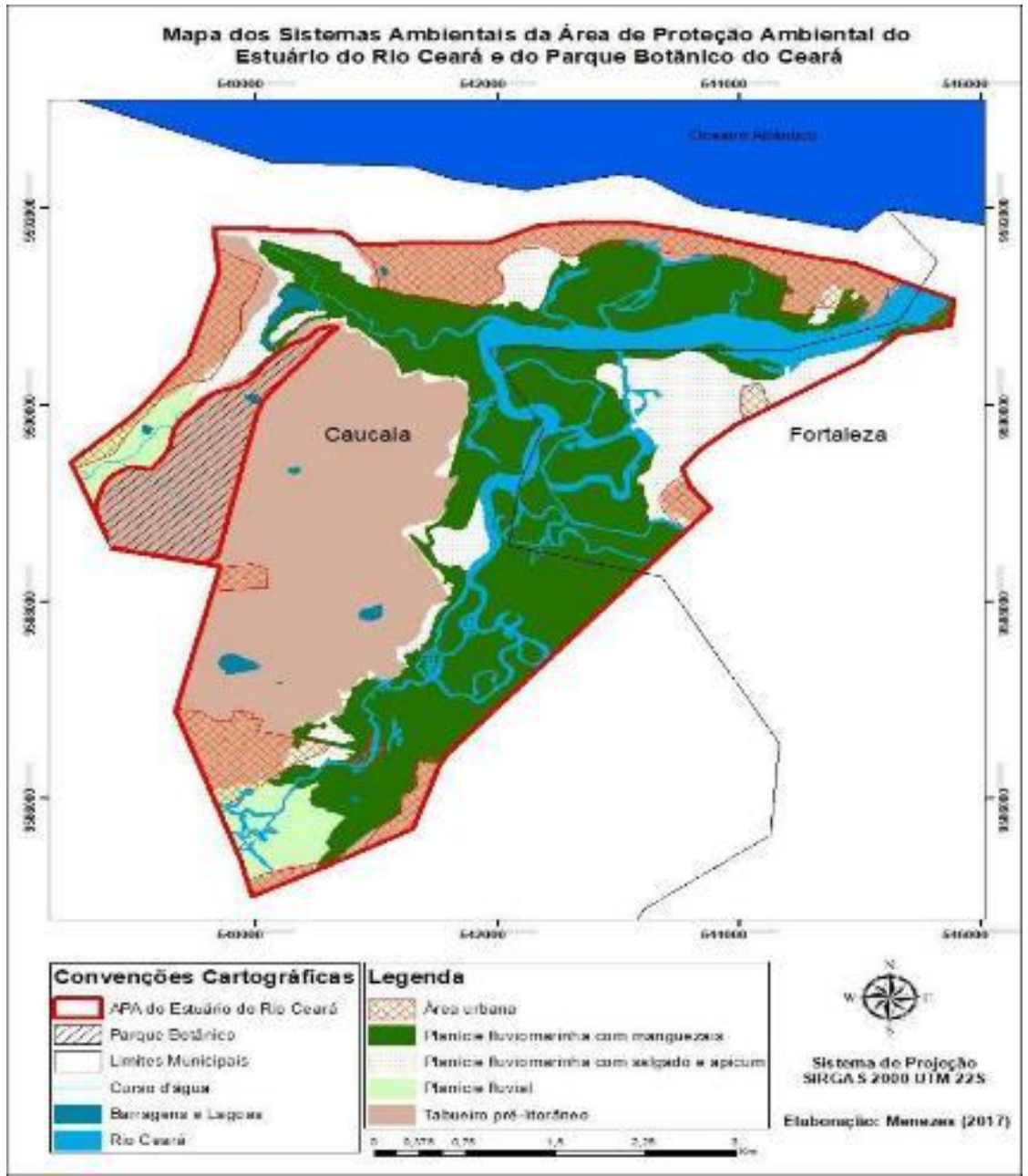

Fonte: Autora (2017).

A finalidade da produção deste mapa é relacionar as informações obtidas com a compartimentação geoambiental para analisar a capacidade de suporte dos sistemas. Desta forma, foram identificados nessas UC: planície fluviomarinha com a presença de manguezais e com salgado e apicum, as áreas com tabuleiros pré-litorâneos e a planície fluvial. A figura 10 faz a sinopse dos sistemas ambientais relacionando a capacidade de suporte dos sistemas, assim como a ecodinâmica, vulnerabilidade, sustentabilidade e os conflitos de uso. 
Figura 10 - Sistemas ambientais, capacidade de suporte e condições de ocupação da APA do Estuário do Rio Ceará e do Parque Botânico

\begin{tabular}{|c|c|c|c|c|}
\hline \multirow{2}{*}{$\begin{array}{l}\text { Sistemas } \\
\text { Ambientais }\end{array}$} & \multicolumn{2}{|c|}{ Capacidade de Suporte } & \multirow{2}{*}{$\begin{array}{l}\text { Ecodinámical } \\
\text { Vulnerabilidade/ } \\
\text { Sustentabilidade }\end{array}$} & \multirow{2}{*}{$\begin{array}{c}\text { Conflitos de } \\
\text { Uso }\end{array}$} \\
\hline & Potencialidades & Limitaçöes & & \\
\hline $\begin{array}{l}\frac{1 . \text { Planicie }}{\text { Litorânea }} \\
\frac{1.1 \text { Planicie }}{\text { Fluviomarinha }}\end{array}$ & $\begin{array}{l}\text { - Ecoturismo } \\
\text { - Extrativismo } \\
\text { vegetal controlado; } \\
\text { - Pesquisa científica; } \\
\text { - Educação } \\
\text { ambiental; } \\
\text { - Pesca artesanal; } \\
\text { - Patrimônio } \\
\text { paisagísticos; } \\
\text { - Abrigo de } \\
\text { embarcações; } \\
\text { - Lazer; } \\
\text { - Preservação da } \\
\text { biodiversidade. }\end{array}$ & $\begin{array}{l}\text { - Restriç̃es à } \\
\text { mineração; } \\
\text {. Solos } \\
\text { excessivamente } \\
\text { drenados e com } \\
\text { baixa fertilidade } \\
\text { natural; } \\
\text { - Restriçöes legais; } \\
\text { - Agricultura; } \\
\text { - Impedimentos à } \\
\text { mecanização; } \\
\text { - Salinidade; } \\
\text { - Inundabilidade. }\end{array}$ & $\begin{array}{l}\text { - Ambientes } \\
\text { fortemente } \\
\text { instáveis; } \\
\text { - Vulnerabilidade } \\
\text { Alta; } \\
\text { - Sustentabilidad } \\
\text { e Baixa. }\end{array}$ & $\begin{array}{l}\text { - Degradação de } \\
\text { manguezais; } \\
\text { - Diminuição da } \\
\text { produtividade } \\
\text { biológica; } \\
\text { - Poluicão dos } \\
\text { recursos hidricos; } \\
\text { - Eliminação e/ou } \\
\text { diminuição de } \\
\text { espécies } \\
\text { piscicolas; } \\
\text { - Despejos de } \\
\text { efluentes, residuos } \\
\text { sólidos e detritos; } \\
\text { - Aterramento; } \\
\text { - Implantação de } \\
\text { salinas. }\end{array}$ \\
\hline $\begin{array}{l}\text { 2. Planicie } \\
\text { Fluvial }\end{array}$ & $\begin{array}{l}\text { - Agroextrativismo; } \\
\text { - Recursos hidricos; } \\
\text { - Agropecuária; } \\
\text { - Mineraçao } \\
\text { controlada; } \\
\text { - Agricultura } \\
\text { irrigada; } \\
\text { - Pesca artesanal; } \\
\text { - Atrativos turisticos } \\
\text { e de lazer. }\end{array}$ & $\begin{array}{l}\text { - Restriçōes legais } \\
\text { associadas com as } \\
\text { matas ciliares; } \\
\text { - Edáficas: drenagem } \\
\text { imperfeita dos solos, } \\
\text { salinização e } \\
\text { inundaçöes } \\
\text { periódicas; } \\
\text { - Mineração } \\
\text { descontrolada; } \\
\text { - Expansão urbana } \\
\text { nos baixos niveis de } \\
\text { terraços fluviais. }\end{array}$ & $\begin{array}{l}\text { Ambientes de } \\
\text { transição } \\
\text { - Vulnerabilidade } \\
\text { Moderada } \\
\text { - Sustentabilidad } \\
\text { e } \\
\text { Moderada }\end{array}$ & $\begin{array}{l}\text { - Degradação de } \\
\text { mata ciliar } \\
\text { desencadeando } \\
\text { processos erosivos } \\
\text { e assoreamento do } \\
\text { rio; } \\
\text { - Poluicäo dos } \\
\text { recursos hídricos; } \\
\text { - Salinizaçäo dos } \\
\text { solos; } \\
\text { - Inundações e } \\
\text { cheias. }\end{array}$ \\
\hline $\begin{array}{l}\frac{3 . \text { Tabuleiros }}{\text { Pré- }} \\
\text { Litorâneos }\end{array}$ & $\begin{array}{l}\text { - Pesquisa cientifica; } \\
\text { - Lavouras de ciclo } \\
\text { curto; } \\
\text { - Agroextrativismo; } \\
\text { - Expansão urbana; } \\
\text { - Mineração } \\
\text { controlada; } \\
\text { - Materiais para } \\
\text { construçäo civil; } \\
\text { - Pecuária } \\
\text { melhorada; } \\
\text { - Instalação viária; } \\
\text { - Áquas } \\
\text { subterrâneas. }\end{array}$ & $\begin{array}{l}\text { Baixa fertilidade dos } \\
\text { solos; } \\
\text { Deficiência hidrica } \\
\text { durante a estiagem. }\end{array}$ & $\begin{array}{l}\text { - Ambientes } \\
\text { medianamente } \\
\text { estáveis } \\
\text {. Vulnerabilidade } \\
\text { Baixa } \\
\text { - Sustentabilidad } \\
\text { e Alta }\end{array}$ & $\begin{array}{l}\text { - Desencadeamento } \\
\text { de processos } \\
\text { erosivos em áreas } \\
\text { degradadas; } \\
\text { - Riscos de poluição } \\
\text { dos recursos } \\
\text { hidricos e dos } \\
\text { solos; } \\
\text { - Mineraçāo } \\
\text { descontrolada; } \\
\text { - Expansão urbana e } \\
\text { impermeabilização } \\
\text { do solo. }\end{array}$ \\
\hline
\end{tabular}

Fonte: Adaptado de SOUZA (2000, 2007).

\section{CONSIDERAÇÕES FINAIS}

A avaliação da capacidade de suporte das UC por meio das condições ecodinâmicas foi imprescindível para se identificar as potencialidades e limitações dos sistemas ambientais do Parque Botânico do Ceará e da APA do Estuário do Rio Ceará. A identificação dos sistemas ambientais e a sua caracterização, utilizando 
como suporte as características geológicas, geomorfológicas, fitoecológicas e a associação de solos dessas UC relacionadas com a área urbana foi importante para avaliar a capacidade de suporte dos sistemas ambientais, pelo fato de as áreas analisadas estarem submetidas à elevada pressão demográfica.

Nota-se que a planície fluviomarinha tanto com a presença de manguezais, quanto de salgado e apicum, está mais susceptível à degradação ambiental, pois apresenta vulnerabilidade alta e sustentabilidade baixa às intervenções humanas neste ambiente. A planície fluvial, apresenta vulnerabilidade e sustentabilidade moderada, e por ser um ambiente de transição, é um sistema ambiental no qual as intervenções sociais devem ser restritivas.

Os tabuleiros pré-litorâneos são classificados como medianamente estáveis, no entanto, as atividades realizadas neste ambiente precisam estar associadas a boas práticas conservacionistas, pois o Parque Botânico e a APA do Estuário do Rio Ceará já apresentaram algumas vezes focos de incêndios que ameaçam a manutenção e o equilíbrio da biodiversidade local.

\section{REFERÊNCIAS}

BRASIL. Ministério do Meio Ambiente, MMA. Sistema Nacional de Unidades de Conservação. Disponível em: <http://www.mma.gov.br/areas-protegidas/sistema-nacional-de-ucs-snuc>. Acesso em: 13 dez. 2017.

COELHO, C. N. C.; CUNHA, L. H.; MONTEIRO, M. de A. Unidades de Conservação: Populações, Recursos e Territórios. Abordagens da Geografia e da Ecologia Política. In: GUERRA, A. J. T.; COELHO, M. C. N. (Org.). Unidades de Conservação: abordagens e características geográficas. 1. ed. Rio de Janeiro: Bertrand, 2009.

SUPERINTENDÊNCIA ESTADUAL DO MEIO AMBIENTE, SEMACE. Área de Proteção Ambiental do Estuário Do Rio Ceará. Disponível em:<http://www.semace.ce.gov.br/2010/12/area-de-protecaoambiental-do-estuario-do-rio-ceara/>. Acesso em 13 dez. 2017.

Parque Botânico do Ceará. Disponível em: <http://www.semace.ce.gov.br/2010/12/ 1644/>. Acesso em 15 dez. 2017.

SOUZA, M. J. N. Bases Naturais e Esboço do Zoneamento Geoambiental do Estado do Ceará. In: Lima, L. C; Souza, M.J.N; Moraes J. O. Compartimentação Territorial e Gestão Regional do Ceará. Fortaleza Editora FUNECE, cap. 1, 2000.

. Compartimentação geoambiental do Ceará. In: SILVA, J. B; CAVALCANTE, T. C.; DANTAS, E. W. C. (Org.) Ceará: um novo olhar geográfico. 2. ed. Fortaleza: Edições Demócrito Rocha, 2007.

SOUZA, M. J. N.; MENELEU NETO, J.; SANTOS, J. de O.; GONDIM, M. S. Diagnóstico Geoambiental do Município de Fortaleza: subsídios ao macrozoneamento ambiental e à revisão do plano diretor participativo. 1. ed. Fortaleza: PMF, 2009.

TRICART, J. Ecodinâmica. Rio de Janeiro, IBGE, Diretoria Técnica, SUPREN, 1977. 